\title{
Clinical Outcomes of Patients with Rheumatoid Arthritis Treated in a Disease Management Program: Real-World Results
}

This article was published in the following Dove Press journal: Open Access Rheumatology: Research and Reviews

\author{
Pedro Santos-Moreno (D) \\ Paola Castillo ${ }^{2}$ \\ Laura Villareal ${ }^{3}$ \\ Carlos Pineda (iD $)^{4}$ \\ Hugo Sandoval (iD ${ }^{5}$ \\ Omaira Valencia (iD) ${ }^{2}$ \\ 'Scientific Direction, Biomab Center for \\ Rheumatoid Arthritis, Bogotá, D.C., \\ Colombia; ${ }^{2}$ Research Department, \\ Biomab Center for Rheumatoid Arthritis, \\ Bogotá, D.C., Colombia; ${ }^{3}$ Medical \\ Direction, Biomab Center for \\ Rheumatoid Arthritis, Bogotá, D.C., \\ Colombia; ${ }^{4}$ Division of Musculoskeletal \\ and Rheumatic Disorders, Instituto \\ Nacional de Rehabilitación Luis \\ Guillermo Ibarra Ibarra, Mexico City, \\ Mexico; ${ }^{5}$ Sociomedical Research Unit, \\ Instituto Nacional de Rehabilitación Luis \\ Guillermo Ibarra Ibarra, Mexico City, \\ Mexico
}

Background: Care models can affect the clinical outcome of patients with rheumatic and musculoskeletal diseases.

Objective: We aimed to compare how an innovative model of a rheumatoid arthritis disease-management program can improve the clinical outcomes of patients compared to a conventional assessment approach.

Methods: We performed a retrospective analysis of real-world data from clinical records of a cohort of 5078 patients diagnosed with rheumatoid arthritis who were followed up at the Center of Excellence in Rheumatoid Arthritis vs the clinical outcomes reported in the Colombian National Registry of Rheumatoid Arthritis.

Results: We found significant differences in the diagnosis and follow-up between the specialized Center program and the usual care reported by the Colombian National Registry $(p<0.005)$, including the evaluation of rheumatoid factor, Anti-citrullinated antibodies Disease Activity Score, Health Assessment Questionnaire, number of visits to the rheumatologist, and clinical outcomes measured by the level of disease activity. In addition, when comparing the Center's clinical outcomes - from baseline to the last follow-up, we found an improvement in the level of disease activity, with patients classified in remission increasing from $20.8 \%$ to $58.5 \%(\mathrm{p}<0.005)$, and a reduction in those with high disease activity from $18 \%$ to $4.7 \%(\mathrm{p}<0.005)$.

Conclusion: Real-world evidence showed that patients with rheumatoid arthritis who underwent follow-up under an innovative disease-management model improved their clinical outcomes compared with those patients in a conventional assessment program. These results could suggest a way of improving health policies for patients with rheumatoid arthritis.

Keywords: disease management, rheumatoid arthritis, quality of life, evidence-based practice, patients

\section{Introduction}

Because of the increasing costs of chronic disease care, several organizations have implemented disease management programs (DMP) attempting to improve the quality of care and reduce overall costs. ${ }^{1,2}$ This situation has stimulated innovative healthcare strategies, including the creation of specialized centers of excellence in rheumatoid arthritis (RA) aimed to optimize results with limited resources. ${ }^{3}$

Conventional care programs for RA patients in most Latin-American countries exhibit various degrees of fragmentation and segmentation, providing low-performing and low-quality services. These programs have suffered from a shortage of qualified
Correspondence: Omaira Valencia Research Department, Biomab Center for Rheumatoid Arthritis, Calle 48 \#13-86, Bogotá, D.C., Colombia Email o.valencial0@uniandes.edu.co 
rheumatology professionals, with restricted access to high-cost medications, rehabilitation programs, and orthopedic interventions. $^{4-7}$

To reduce the burden of RA, a model of care based on early diagnosis and effective DMP should incorporate quality improvement methodologies and contextual factors dependent on the individual, environment, and healthdisease process, as well as pharmacological and nonpharmacologic treatment strategies. ${ }^{8,9}$

Also, a team of healthcare-related professionals should deliver such an integrated care model with a multidisciplinary approach, within an environment of quality, opportunity, accessibility, and safety. ${ }^{1,2,10}$

In Colombia, the healthcare system operates through a mixed public-private model regulated by the Ministry of Health. This system covers $94.6 \%$ of the population and includes benefits for high-cost diseases including rheumatoid arthritis for diagnosis, treatment and the access to biological drugs if it is required. ${ }^{11,12}$ Over time it has become clear that a large variety of contracts are available between payers and providers, with gaps in the costs in the health market. ${ }^{6}$ As a result, there is fragmentation and a reduction in the quality of care. ${ }^{13}$

To improve healthcare and regulate cost, the Colombian Ministry of Health developed a national policy for integrating the healthcare system, including the creation of a National Administrative Registry of Rheumatoid Arthritis (NARRA) to evaluate the status of patients living with RA as reported by payers and healthcare providers. ${ }^{6,14}$

Through this process, real-world data offers an opportunity to stakeholders to improve policy and programs with information on healthcare from multiple sources outside typical clinical research settings, including electronic health records (EHR), claims and billing data, and disease registries. $^{15}$

Implementing this policy requires high-quality healthcare providers with available DMPs to reduce barriers of access and minimize the fragmentation of medical services through the delivery of integrated healthcare services. ${ }^{6}$ This article aimed to offer some real-world evidence regarding how an integrated DMP may be able to improve the outcomes of patients with RA compared to conventional approaches such as the NARRA.

\section{Methods}

We developed a retrospective real-world data analysis from a detailed review of electronic health records of 5078 patients with RA who regularly visited a specialized
Center under a model of DMP dedicated to RA care in Bogotá, Colombia, between July 1, 2015 and June 30, 2016, patients were diagnosed in the last year or before. A rheumatologist confirmed the diagnosis of RA according to the American College of Rheumatology and European League Against Rheumatism 2010 Classification criteria. All patients were followed up on and received treatment in a DMP protocol under a treat-to-target (T2T) strategy . ${ }^{16}$ The data collected were anonymized to protect the confidentiality and privacy of patients.

We then compared the gathered information with the results obtained from the "Situación de la artritis reumatoide en Colombia 2016" ("Situation of rheumatoid arthritis in Colombia 2016") a document developed and edited by Colombian High-Cost Disease Office (Spanish acronym - Cuenta de Alto Costo) nominated in this work as the National Registry of Rheumatoid Arthritis (NARRA), this registry report data for 68,247 patients with RA.

There were 89 variables collected on demographics, concomitant diagnoses, treatment, and clinical outcomes; including age, gender, disease duration, comorbidities, type of pharmacologic treatment, measurements of disease activity, the disease activity score (DAS28), ${ }^{17}$ and functionality by the Health assessment Questionary (HAQ). ${ }^{18}$ The reporting of this information by healthcare providers to the Colombian High-Cost Disease Office is mandatory by Colombian law.

\section{The Disease Management Program}

We treated patients under DMP to provide a multidisciplinary healthcare approach, comprising of the following healthcare areas: rheumatology, nutrition, psychology, physical and occupational therapy, physical medicine, and rehabilitation according to their RA activity status (Table 1).

We followed patients under standard Treat-to-Target (T2T) strategies. We considered a DAS28 score $<2.6$, $\geq 2.6$ and $<3.2, \geq 3.2$ and $<5.1$, and $\geq 5.1$ as an indicator of remission, low disease activity (LDA), moderate (MDA), and high disease activity (HDA), respectively.

The clinical follow-up program, according to the DAS28 cut-off values, was designed and followed in the specialized Center, with rheumatologist evaluations every 3-5 weeks (DAS28 $\geq 5.1$ ); 6-8 weeks (DAS28 between $\geq 3.2$ and $<5.1$ ), and 9-12 weeks (DAS28<3.2). Tender and swollen joint counts and DAS28 using the erythrocyte sedimentation rate were calculated on each visit.

The pharmacologic and non-pharmacologic treatment program required adjustments with values based on the 
Table I Specialized Center Disease-Management Program Number of Visits per Year

\begin{tabular}{|l|l|l|l|}
\hline \multirow{2}{*}{ Speciality } & \multicolumn{3}{|l|}{ Disease Activity } \\
\cline { 2 - 4 } & High & Moderate & Low \\
\hline Rheumatology & 12 & 6 & 4 \\
Physical Medicine and Rehabilitation & 4 & 3 & 2 \\
Nutrition & 2 & 1 & 1 \\
Psychology & 4 & 3 & 2 \\
Physical therapy & 6 & 4 & 2 \\
Occupational therapy & 6 & 4 & 2 \\
Educational sessions & 6 & 4 & 2 \\
\hline
\end{tabular}

standards developed for the specialized Center, according to REAL-PANLAR (Project of implementation and accreditation of centers of excellence in rheumatoid arthritis throughout Latin America) ${ }^{2}$.

The frequency of visits to the multidisciplinary healthcare team in the previous year was established according to the results of disease activity and adjusted to the needs and availability of the individual patient. We also included educational programs for patients and blood tests in the DMP (Table 1).

\section{Statistical Analysis}

We performed statistical analysis in 3 phases. First, quantitative data of normal distributions are presented as the means and standard deviations (SDs). Non-normally distributed data are presented as the medians and ranges. Qualitative data are presented as frequencies and percentages. Second, we calculated the difference between the principal characteristics of the population and DAS28 and HAQ values between the specialized Center and NARRA using Chi2 test. Third, we compared the median DAS28 values at baseline and the last visit using Fisher's exact test, assuming a non-normal distribution for DAS28 values. Differences were considered significant at $p$-values $<0.05$. We used the STATA v. 13 software for statistical analysis.

\section{Results}

Table 1 shows the frequency of visits per year for any specialization according to the level of disease activity (at least 4 visits per year to the rheumatologist for patients with LDA and 1 or 2 visits to the interdisciplinary team). Table 2 summarizes the differences of the model based on DMP and conventional methods in the country reported by NARRA.

Regarding DMP, we found statistical differences in RF and ACPA evaluation in the diagnosis and performance of DAS28 and HAQ in a specialized center compared to those in NARRA. The percentage of patients in whom we calculated the DAS28 in the Center was $99 \%$. This figure was much higher than the Colombian national average (39.8\%) (Table 2).

In addition, the application rate of HAQ was higher for the specialized center group $(71.7 \%)$ than that reported by NARRA (21.2\%). Finally, we found differences in the number of visits to the rheumatologist per year: 4 for the specialized center compared with 1 visit per year in the NARRA report.

Table 3 summarizes the demographic and clinical characteristics of the 5078 patients with RA evaluated and prospectively followed up at the specialized center between 2015 and 2016, with 1380 patients newly diagnosed during this period. The age group of 50-65 years made up $45 \%$ of the total population. Disease duration was 3 years on

Table 2 Comparisión of the DMP in the Specialized Center and the Usual Care for RA Reported by NARRA

\begin{tabular}{|c|c|c|c|c|c|}
\hline & \multicolumn{2}{|c|}{ Specialized Center } & \multicolumn{2}{|l|}{ NARRA } & \multirow[t]{2}{*}{$P$ value } \\
\hline & Freq. & Percent & Freq. & Percent & \\
\hline \multicolumn{6}{|l|}{ Diagnosis* } \\
\hline Performance of RF at diagnosis time & $|25|$ & 92.5 & 2819 & 76 & 0.0001 \\
\hline Performance of ACPA at diagnosis time & 1315 & 96.1 & 890 & 24 & 0.0001 \\
\hline \multicolumn{6}{|l|}{ Follow-up** } \\
\hline Percentage in which DAS28 was obtained & 5027 & 99.0 & 27,191 & 39.8 & 0.0057 \\
\hline HAQ measurement & 3641 & 71.7 & 14,519 & 21.3 & 0.0051 \\
\hline Number of rheumatology visits per year & 4 & $* * *$ & 1 & $* * *$ & $* * *$ \\
\hline Number of visits with Interdisciplinary team & 2 & $* * *$ & Not reported & $* * *$ & $* * *$ \\
\hline
\end{tabular}

Notes: *Specialized center $n=1385$ NARRA $n=3709$. **Specialized center $n=5078$ NARRA $n=68,247$. ***Not applicable, Number of visits to interdisciplinary team are not available in the NARRA. 
Table 3 Demographic and Clinical Characteristics of the Population in the Specialized Center and NARRA

\begin{tabular}{|c|c|c|c|c|c|}
\hline \multirow[t]{3}{*}{ Variable } & \multicolumn{2}{|c|}{ Specialized Center } & \multicolumn{2}{|l|}{ NARRA } & \multirow[t]{3}{*}{ P-value } \\
\hline & \multicolumn{2}{|l|}{$n=5078$} & \multicolumn{2}{|c|}{$n=68,247$} & \\
\hline & n/Mean & Percent/SD & n/Mean & Percent/SD & \\
\hline Age* & 59 & 1.28 & 57 & 13.48 & 0.1320 \\
\hline \multicolumn{6}{|l|}{ Sex } \\
\hline Female & 4155 & 81.8 & 57,372 & 84.1 & 0.1392 \\
\hline Male & 923 & 18.2 & 10,875 & 15.9 & 0.1394 \\
\hline Disease duration (years)* & 3 & 3.4 & 8 & 8.44 & 0.0020 \\
\hline \multicolumn{6}{|l|}{ Comorbidities at cohort entry+ } \\
\hline Overweight & $165 \mid$ & 32.5 & 1032 & 27.8 & 0.0031 \\
\hline Obesity & 812 & 16 & 452 & 12.2 & 0.0410 \\
\hline Hypertension & 1263 & 24.9 & 839 & 22.6 & 0.0370 \\
\hline Diabetes & 231 & 4.6 & 238 & 6.4 & 0.0065 \\
\hline Chronic Kidney disease & 73 & $\mathrm{I} .4$ & 155 & 4.2 & 0.0001 \\
\hline Cerebrovascular disease & 49 & 1 & 90 & 2.4 & 0.0153 \\
\hline \multicolumn{6}{|l|}{ Type of Treatment } \\
\hline Only corticoids & 534 & 10.5 & 13,226 & 19 & 0.0010 \\
\hline cDMARD & 3508 & 69.1 & 44,450 & 65.1 & 0.0330 \\
\hline bDMARD & 204 & 4 & $|0,57|$ & 15.5 & 0.0010 \\
\hline cDMARD combined bDMARD & 832 & 16.4 & ** & ** & ** \\
\hline
\end{tabular}

Notes: *Results in means and Standard Deviation (SD). Age reported in the last visit. +Data of comorbidities of NARRA was calculated just in incident population 3709. **No data available.

average, and the mean follow-up period was 2 years. Regarding comorbidities, we found that being overweight, obesity, and high blood pressure were the most common conditions present at the time of diagnosis or developed during follow-up.

Up to $2 / 3 \mathrm{rds}(\mathrm{n}=3508 ; 69.1 \%)$ of patients were treated with conventional disease-modifying antirheumatic drugs (cDMARDs), and 204 (4.0\%) were treated with biologic DMARDs (bDMARDs), whereas $16.4 \%$ were treated with a cDMARD-bDMARD combination. Thus, $20.4 \%$ $(n=1036)$ of the patient population was treated with biologic agents. A significant difference was found in the use of DMARD and bDMARD in the RA specialized center compared to that in NARRA (Table 3 ).

Likewise, in the specialized center, the proportion of patients classified as remission increased from $20.8 \%$ to $50.5 \%$ between baseline and the last assessment, while the proportion of persons with HDA showed a significant reduction from $18.0 \%$ to $4.7 \%(\mathrm{p}<0.005)$ (Table 4$)$.

At last, a comparison of disease activity status between patients who received their healthcare in the specialized center compared to that in the NARRA systems revealed a significant difference in the percentage of patients classified as LDA over the Colombian national registry. The Colombian NARRA (the conventional healthcare model) showed a higher percentage of patients with HDA compared with the specialized center with DMP results (Table 5).

\section{Discussion}

The deficiencies of most Latin American health systems relegate the quality of patients' care to the background, as

Table 4 Outcomes of Disease Management at Baseline and the Last Measurement of Patients with More Than Six Months in the Specialized Center

\begin{tabular}{|l|l|l|l|l|l|}
\hline \multirow{2}{*}{} & \multicolumn{2}{|l|}{ Diagnosis } & \multicolumn{2}{l|}{ Follow-Up } & \multirow{2}{*}{ p-value } \\
\cline { 2 - 4 } & Freq. & Percent & Freq. & Percent & \\
\hline \multicolumn{5}{|l}{ Disease activity according to DAS28 } \\
\hline Remission & 835 & 20.8 & 2346 & 58.5 & 0.004 \\
Low & 1045 & 26.1 & 692 & 17.3 & 0.013 \\
Moderate & 1406 & 35.1 & 781 & 19.5 & 0.002 \\
High & 722 & 18.0 & 189 & 4.7 & 0.001 \\
\hline Total & 4008 & 100.00 & 4008 & 100 & \\
\hline
\end{tabular}

Notes: DAS28 $<2.6$ Remission; DAS28 $\geq 2.6$ and $<3.2$ low disease activity; moderate between DAS28 $\geq 3.2$ and $<5$. I; a DAS28 $\geq 5$. I high disease activity. Follow-up: Last measurement in the study year (July 2015-June 2016). 
Table 5 Comparison of Disease Activity Status Between Different Rheumatology Practices

\begin{tabular}{|l|l|l|l|}
\hline $\begin{array}{l}\text { Disease Activity } \\
\text { Classification }\end{array}$ & $\begin{array}{l}\text { Specialized } \\
\text { Center }\end{array}$ & NARRA & \multirow{2}{*}{ P-value } \\
\cline { 2 - 3 } & $\mathbf{n = 5 0 7 8}$ & $\mathbf{n}=\mathbf{2 7 , 1 9 1}$ & \multirow{2}{*}{} \\
\cline { 2 - 3 } & $\%$ & $\%$ & \\
\hline LDA (Low Disease Activity) & 75.8 & 70.1 & 0.001 \\
MDA (Moderate Disease & 19.5 & 22.5 & 0.012 \\
Activity) & & & \multirow{2}{*}{0.001} \\
HDA (High Disease Activity) & 4.2 & 7.3 & 0.3 \\
\hline
\end{tabular}

Notes: DAS28 score $<3.2$ low disease activity; a DAS28 score $\geq 3.2$ and $<5.1$ moderate disease activity; a DAS28 score $\geq 5$. I high disease activity.

some of their economic-administrative features received priority over chronic and potentially disabling conditions. ${ }^{1}$ This situation has stimulated the emergence of innovative healthcare strategies, like the creation of specialized centers with high standards, aimed to seek quality results. ${ }^{19}$

This study supports the rising importance of evidencebased, real-world data in Latin American countries like Colombia, through the follow-up of a significant cohort of patients under a DMP. This first exercise allows us to compare the clinical outcomes between innovative and more conventional practices.

We found that the specialized center results in terms of DAS28 (99\%) performance, was higher than the Colombian NARRA average (39.8\%) and even above the American College of Rheumatology (ACR) Rheumatology Informatics System for Effectiveness (RISE) in the United States results $(52.1 \%) .{ }^{15}$ Consequently, our data clearly showed a higher number of patients with LDA and compared to the Colombian registry.

These results also suggest that the implementation of a DMP, incorporating a team of allied health professionals and flexible healthcare model adaptable to the disease activity status, resulted in a significant gap regarding the mean number of follow-up visits to the rheumatologist (4 per year in the specialized center compared to 1 in the NARRA). We assumed this gap may be related to access barriers to rheumatology services, such as a lack of timely and appropriate referral programs, workforce shortages, the concentration of specialists in the metropolitan area, and underserved country areas with a lower likelihood of applying T2T strategies. In addition, the study about integrated care in musculoskeletal disorders suggest that patients attended under an integrative approach with more focus on patients needs, improves the clinical outcomes as the quality of life. ${ }^{20}$
We are aware that most costs of RA medical attention are due to pharmacologic treatment. In this field, the advent of new therapies (biologic medicines and small-molecule therapeutics) has pushed healthcare expenses. ${ }^{21,22}$ Therefore, improvements in disease activity, functional status, and reducing disability through a comprehensive DMP may contribute to savings in direct and indirect costs associated with early diagnosis, systematic medical management, and RA treatment. ${ }^{23,24}$ Health insurers will need to become more cautious about specialty drug use, focusing on cost-saving options such as DMP, including drug distribution channels, contracting activities, and care coordination. ${ }^{25}$

Also, most patients with RA are over 50 years of age. This aging population will develop greater risks and have a higher number of hospitalizations in contrast with a younger population. Evidence shows that patients with multiple comorbidities can cost up to 7 times as much as required for patients with a single chronic condition. ${ }^{23,26}$

In this context, providers and stakeholders need to develop healthcare services to anticipate and prevent complications and maintain stable underlying chronic conditions to preserve functional capacity, minimizing the disease impact on patients and lowering the burden on the national healthcare system. ${ }^{27}$

The DMP may represent a potential solution to the fragmentation of RA care at the national level, reducing timely access to the healthcare system, and improving RA management (with attention to comorbidities and risk factors). This study aligned with other analyses revealing that when the disease course is monitored, and medications are adjusted accordingly in conjunction with rehabilitation programs addressed by a multidisciplinary healthcare team, the comorbidities often observed during RA may be prevented or, if already present, may have a lower impact on clinical outcomes. ${ }^{28}$

An important factor increasing the cost of RA care is the use of newer biologic medications. Our results showed that $20 \%$ of patients were treated with one of these agents, a percentage higher than the $16 \%$ reported by the NARRA at the national level. This may be explained by the fact that the NARRA is a relatively new survey instrument and may under-report data.

Another possible reason may entail fewer access barriers to high-cost treatments in the Center program, compared to individuals seen in primary-care settings or at non-specialized medical clinics for RA, who are required to wait for extended periods for administrative authorization and experience decreased availability of biologic 
medications from their insurance companies because of the channel of distribution and others barriers imposed by insurers, this is characteristic in other countries of the region. $^{29,30}$

Objectives of DMP include the evaluation of functional disability, with remission goals quantified using clinical instruments. ${ }^{5,31}$ HAQ and DAS28 are the most used instruments in RA clinical trials and are also important in DMP patient-centered care. $^{32,33}$

In the conventional NARRA, which includes data from primary-care physicians, independent rheumatologists, and hospital-based clinics, DAS28 and HAQ may not be regularly obtained, since the importance of these metrics in daily clinical practice may not be recognized as a measurement of the effectiveness of healthcare programs or as an outcome of quality from the patient's perspective. ${ }^{34,35}$

This first analysis included 3 remarkable limitations. First, there was no remission data of the patients in the Center and NARRA. Second, the differences in the clinical status as the time of disease evolution between the Specialized center and the NARRA could be a limitation; however, this condition has an effect to achieve remission and remission is not compare, for this comparison all patients with DAS2 $8<3.2$ were classified as LDA. Other clinical significance differences as the percentage of chronic kidney disease has not greater effects in the disease activity. Since this is a clinically relevant finding, its absence represents an additional weakness in this analysis which was derived from their retrospective approach. Third, it is also important to point out that this is one of the first comparisons, so there are risks of bias in results analysis that we have not assessed.

Notwithstanding preceding data, these outcomes derived from real-world data may offer stakeholders and clinicians an opportunity for reflection on how to improve policies involving the integration of healthcare components, including patient access to medical attention and drugs, disease-activity and functional monitoring, and the appropriate adjustment of treatment based on a treat-totarget strategy.

\section{Conclusions}

We have shown some benefits of DMP for improving the clinical status in patients with RA. Since systematic measurements of the disease activity and functional status of RA patients provides indicators of good clinical practice and quality of care, this process can be an option to consider for RA healthcare providers.
Results from RA patients followed up on in the specialized Colombian Center evidenced that a healthcare model based on a DMP may improve clinical outcomes, reduce access barriers and time for receiving medical attention by a rheumatologist and other allied health professionals, compared with other conventional assessment practices as the NARRA.

\section{Abbreviations}

Center, Center of Excellence in Rheumatoid Arthritis; NARRA, National Registry of Rheumatoid Arthritis; RISE, Rheumatology Informatics System for Effectiveness; EHR, electronic health records; T2T, treat to target; DAS28, Disease Activity Score; HAQ, Health Assessment Questionnaire; LDA, low disease activity; MDA, moderate disease activity; HDA, high disease activity; ACR, American College of Rheumatology; cDMARD, conventional disease-modifying activity drugs; bDMARD, biologic disease-modifying activity drugs; PANLAR, Pan American League of Associations of Rheumatology; EBP, evidence based on practice.

\section{Ethics Disclaimer}

This study complied with the ethical requirements of the Declaration of Helsinki. According to Resolution 8430 (1993) of the Ministry of Health, this research presents no risks to patients; the study was approved by the Institutional Review Board of BIOMAB, act 004/2018 (code GC.IN.01.FR.03). All patients had previously signed an informed consent for data use; the database was anonymized to protect the confidentiality and privacy of patients.

\section{Acknowledgments}

Authors want to acknowledge the work of and give thanks to doctor Oscar Bernal, professor of the Universidad de los Andes, Colombia, for the revision as an expert in health systems and acknowledge the BIOMAB team for the administrative support.

\section{Disclosure}

Dr Pedro Santos-Moreno reports grants, personal fees, and non-financial support from Pfizer, Janssen, and Biopas UCB, grants and non-financial support from Abbvie, nonfinancial support from Bristol and Roche, personal fees and non-financial support from Sanofi and Lilly, outside the submitted work. The authors report no other potential conflicts of interest for this work. 


\section{References}

1. Santos-Moreno P, Castañeda O, Garro B, Flores D, Sánchez G, Castro C. From the model of integral attention to the creation of centers of excellence in rheumatoid arthritis. Clin Rheumatol. 2015;34(S1):71-77. doi:10.1007/s10067-015-3017-8

2. Santos-Moreno P, Galarza-Maldonado C, Caballero-Uribe CV, et al. REAL-PANLAR project for the implementation and accreditation of centers of excellence in rheumatoid arthritis throughout Latin America: a consensus position paper from REAL-PANLAR group on improvement of rheumatoid arthritis care in Latin America establishing centers of excellence. $J$ Clin Rheumatol. 2015;21(4):175-180. doi:10.1097/RHU.0000000000000247

3. Santos-Moreno P, Caballero-Uribe CV, Cardiel MH, et al. A consensus position paper from REAL-PANLAR group about the methodological approach for the accreditation process of centers of excellence in rheumatoid arthritis in Latin America. J Clin Rheumatol. 2019;25(1):54-58.

4. Santos-Moreno PI, de la Hoz-valle J, Villarreal L, Palomino A, Sánchez G, Castro C. Treatment of rheumatoid arthritis with methotrexate alone and in combination with other conventional DMARDs using the T2T strategy. A cohort study. Clin Rheumatol. 2015;34 (2):215-220. doi:10.1007/s10067-014-2794-9

5. Stoffer MA, Smolen JS, Woolf A, et al. Development of patient-centred standards of care for rheumatoid arthritis in Europe: the eumusc.net project. Ann Rheum Dis. 2014;73(5):902-905. doi:10.1136/annrheumdis-2013-203743

6. Ministerio de Salud y Protección S. Política de atención integral en salud. Minsalud; 2016:1-94.

7. Pan American Health Organization. Access to High-Cost Medicines in the Americas: Situation, Challenges and Perspectives. 2010:81.

8. Hu H, Luan L, Yang K, Li S-C. Burden of rheumatoid arthritis from a societal perspective: a prevalence-based study on cost of illness for patients with rheumatoid arthritis in China. Int J Rheum Dis. 2018;21(8):1572-1580.

9. Barrera Castro SM, Suárez Moya ÁMG, Mora LM, Cardona C, Jáuregui Cuartas EA, Muñoz Urrego YA. Aproximación de discapacidad en artritis reumatoide. Resultados de un programa de atención integral. Rev Colomb Reumatol. 2017;24(3):138-144.

10. Santos-Moreno P, Caballero-Uribe CV, Massardo ML, et al. Systematic and progressive implementation of the centers of excellence for rheumatoid arthritis: a methodological proposal. Clin Rheumatol. 2017;36(12):2855-2858.

11. Valencia O, Lopes G, Sánchez P, Acuña L, Uribe D, González J. Incidence and prevalence of cancer in Colombia: the methodology used matters. $J$ Glob Oncol. 2017;4:1-7. Available from: http://asco pubs.org/doi/10.1200/JGO.17.00008. Accessed October 20, 2020.

12. Ministerio de Salud y Protección Social. Resolución 5926 De 2014. 2014:1-48.

13. Bossert T. Inter-American Development Bank, (IDB Technical Note ; 585).Comparative Review of Health System Integration in Selected Countries in Latin America. Available from: https://publications.iadb. org/en/publication/11898/comparative-review-health-system-integra tion-selected-countries-latin-america. January, 2014.

14. MSPS. Resolucion 1393 De 2015 [Internet]. Colombia; 2015:14. Available from: https://cuentadealtocosto.org/site/images/Resolucion 1393 de 2015 - ARTRITIS.pdf. Accessed October 20, 2020.

15. Yazdany J, Myslinski R, Johansson T, Kazi S. OP0068 practices participating in the ACR'S rheumatology informatics system for effectiveness (RISE) national registry show improvements in quality of care. Ann Rheum Dis. 2017;79:2-80. Available from: http://ard. bmj.com/lookup/doi/10.1136/annrheumdis-2017-eular.5640.

Accessed October 20, 2020

16. Smolen JS, Landewé R, Breedveld FC, et al. EULAR recommendations for the management of rheumatoid arthritis with synthetic and biological disease-modifying antirheumatic drugs: 2013 update. Ann Rheum Dis. 2014;73(3):492-509. doi:10.1136/annrheumdis-2013204573
17. Prevoo MLL, Van'T Hof MA, Kuper HH, Van Leeuwen MA, Van De Putte LBA, Van Riel PLCM. Modified disease activity scores that include twenty-eight-joint counts development and validation in a prospective longitudinal study of patients with rheumatoid arthritis. Arthritis Rheum. 1995;38(1):44-48. doi:10.1002/ art. 1780380107

18. Bruce B, Fries JF. The stanford health assessment questionnaire: dimensions and practical applications [internet]. Health Qual Life Outcomes. 2003;1:20. doi:10.1186/1477-7525-1-20

19. Pilar C, Camargo B, Eliana L, Ruiz G. Análisis de la Variación de los Costos de los Medicamentos de Artritis Reumatoide en Una eps en la Ciudad de Bogotá, 2009 - 2011 [Internet]. Pontificia Universidad Javeriana; 2012. Available from: https://repository.javeriana.edu.co/ bitstream/handle/10554/1847/BecerraCamargoClaudiaPilar2012.pdf? sequence $=1$. Accessed October 20, 2020.

20. Lurie JD, Bell JE, Weinstein J. What rate of utilization is appropriate in musculoskeletal care? Clin Orthop Relat Res. 2009;467(10):250611. doi:10.1007/s11999-009-0889-4.

21. Badamgarav E, Croft JD, Hohlbauch A. Effects of disease management programs on functional status of patients with rheumatoid arthritis. Arthritis Rheum. 2003;49(3):377-387. doi:10.1002/ art.11120

22. Gleason PP, Alexander GC, Starner CI, et al. Health plan utilization and costs of specialty drugs within 4 chronic conditions. $J$ Manag Care Pharm. 2013;19(7):542-548.

23. Kawatkar AA, Jacobsen SJ, Levy GD, Medhekar SS, Venkatasubramaniam KV, Herrinton LJ. Direct medical expenditure associated with rheumatoid arthritis in a nationally representative sample from the medical expenditure panel survey. Arthritis Care Res. 2012;64(11):1649-1656.

24. Brooks PM. The burden of musculoskeletal disease-a global perspective. Clin Rheumatol. 2006;25(6):778-781.

25. Michet CJ, Strobova K, Achenbach S, Crowson CS, Matteson EL. Hospitalization rates and utilization among patients with rheumatoid arthritis: a population-based study from 1987 to 2012 in Olmsted County, Minnesota. Mayo Clin Proc. 2015;90(2):17 6-183.

26. Briggs AM, Fary RE, Slater H, et al. Disease-specific knowledge and clinical skills required by community-based physiotherapists to co-manage patients with rheumatoid arthritis. Arthritis Care Res. 2012;64(10):1514-1526. doi:10.1002/acr.21727

27. Voshaar MJH, Nota I, Van De Laar MAFJ, Van Den Bemt BJF. Patient-centred care in established rheumatoid arthritis. Best Pract Res Clin Rheumatol. 2015;29(4-5):643-663. doi:10.1016/j. berh.2015.09.007

28. Laires PA, Exposto F, Mesquita R, Martins AP, Cunha-Miranda L, Fonseca JE. Patients' access to biologics in rheumatoid arthritis: a comparison between Portugal and other European countries. Eur $J$ Heal Econ. 2013;14(6):875-885. doi:10.1007/s10198-012-0432-5

29. Ruiz R, Strasser-Weippl K, Touya D, et al. Improving access to high-cost cancer drugs in Latin America: much to be done. Cancer. 2017;123(8):1313-1323.

30. Michaud K, Berglind N, Franzén S, et al. Can rheumatoid arthritis (RA) registries provide contextual safety data for modern RA clinical trials? The case for mortality and cardiovascular disease. Ann Rheum Dis. 2016;75(10):1797-1805.

31. Navarro-Compán V, Smolen JS, Huizinga TWJ, et al. Quality indicators in rheumatoid arthritis: results from the METEOR database. Rheumatol. 2015;54(9):1630-1639.

32. Mahmood S, Lesuis N, Van Tuyl LHD, Van Riel P, Landewé R. Quality in rheumatoid arthritis care. Best Pract Res Clin Rheumatol. 2015;29(4-5):664-679. doi:10.1016/j.berh.2015.09.009

33. El Miedany Y. Adopting patient-centered care in standard practice: pROMs moving toward disease-specific era. Clin Exp Rheumatol. 2014;32(14):S40-S46. 
34. Wang BCM, Hsu P-N, Furnback W, et al. Estimating the economic burden of rheumatoid arthritis in Taiwan using the National Health Insurance Database. Drugs Real World Outcomes. 2016;3 (1):107-114. doi:10.1007/s40801-016-0063-8
35. Ministerio de Salud. Resolución 8430 De 1993. Vol. 1993. Minist Salud y Protección Soc República Colomb; Octubre 4, 1993:1-19.

\section{Publish your work in this journal}

Open Access Rheumatology Research and Reviews is an international, peer-reviewed, open access journal publishing original research, reports, editorials, reviews and commentaries on all aspects of clinical and experimental rheumatology in the clinic and laboratory including the following topics: Pathology, pathophysiology of rheumatological diseases; Investigation, treatment and management of rheumatological diseases; Clinical trials and novel pharmacological approaches for the treatment of rheumatological disorders. The manuscript management system is completely online and includes a very quick and fair peer-review system, which is all easy to use. Visit http://www.dovepress.com/testimonials.php to read real quotes from published authors. 